EXTENDED REPORT

\title{
Are cytokine gene polymorphisms associated with outcome in patients with idiopathic intermediate uveitis in the United Kingdom?
}

\author{
M R Stanford, R W Vaughan, E Kondeatis, Y Chen, C E Edelsten, E M Graham, G R Wallace
}

Br J Ophthalmol 2005;89:1013-1016. doi: 10.1136/bjo.2004.057620

See end of article for authors' affiliations

Correspondence to: Dr Graham Wallace, Academic Unit of Ophthalmology, Division of Immunity and Infection, University of Birmingham Birmingham B15 2T, UK; g.r.wallace@bham.ac.uk

Accepted for publication 19 February 2004 of cytokines, either locally within the eye or systemically, may Background/aim: Competing levels of cytokines, either locally within the eye or systemically, may
influence the eventual outcome of ocular inflammation. Polymorphism in the promoter part of the genes controlling cytokine production may result in either higher or lower production of the relevant cytokine to a given stimulus. The authors hypothesised that such polymorphisms may relate to visual outcome in patients with idiopathic intermediate uveitis.

Methods: DNA was obtained from 125 patients with idiopathic intermediate uveitis and analysed for the interleukin 10 IL-10-1082G/A and IL-10-819C/T, and interferon $\gamma$ IFN $\gamma$ 874T/A gene polymorphisms. Associations with disease were calculated by both allelic frequency and haplotype analysis, and associations between ocular disease outcomes and the presence of polymorphisms were identified. A bad outcome was defined as loss of vision $<6 / 12$ Snellen in both eyes at 5 years from presentation when the eyes were quiet.

Results: An initial screen showed that the 874T allele of the IFN $\gamma$ gene was more prevalent in patients than controls $\left(\chi^{2}=7.9 ; p=0.004\right.$ OR 1.7; 95\% Cl 1.2 to $2.6(P c=0.02)$, whereas the IL-10-1082/-819 AT haplotype of the interleukin 10 (IL-10) gene was not. Analysis of disease outcome showed an association between IL-10-1082 AA homozygosity and bad outcome $\left(\chi^{2}=13 ; p=0.0003\right)$. Moreover, the two cytokine polymorphisms taken together showed that up to $75 \%$ of patients with a poor visual outcome had the combined IFN $\gamma$ 874TA or $\Pi$ genotype together with the IL-10-1082AA genotype $\left(\chi^{2}=13.2\right.$ $\mathrm{p}=0.0008 \mathrm{OR} 6.4 ; 95 \% \mathrm{Cl} 1.85$ to $23.6 \mathrm{Pc}=0.1)$.

Conclusion: These results show that disease outcome in intermediate uveitis may be partly determined by a complex interplay between cytokine genes and these results may have implications for future treatment with biological agents that target these cytokines.
I ntermediate uveitis is one of a number of sight threatening inflammatory diseases characterised by breakdown of the blood-retinal barrier with leucocytic infiltration of the retina and macular oedema. ${ }^{1}$ It has a variety of clinical presentations, systemic disease associations, and long term effects on visual function. Intermediate uveitis is classically linked to multiple sclerosis and sarcoidosis but may be idiopathic where there is no association with inflammatory disease outside of the eye. Intermediate uveitis is generally considered to be an autoimmune, cell mediated, organ specific disease based on the findings of autoreactive $\mathrm{T}$ cells and antibodies in patients, the response of the disease to immunosuppression and the existence of experimental models that share many of the clinical and immunological features of the human disease. ${ }^{1-3}$

It is increasingly apparent that inflammatory reactions can be profoundly influenced by the cytokine milieu in which they occur. For instance, interferon gamma (IFN $\gamma$ ) is associated with a Thl pro-inflammatory phenotype and has been shown to regulate expression of experimental autoimmune uveitis (EAU). ${ }^{4}$ IFN $\gamma$ production is influenced by polymorphism of a dinucleotide repeat in the promoter part of the IFN $\gamma$ gene that defines high IFN $\gamma$ production, and by a single nucleotide polymorphism (SNP) A874T that is in absolute correlation with the repeat. ${ }^{5}{ }^{6}$ The presence of this SNP confers the ability to produce IFN $\gamma$ and there is a gene dosage effect so that homozygotes produce more of the cytokine than heterozygotes or those in whom the SNP is not present. The clinical relevance of this finding has been shown in transplantation biology where the presence of IFN $\gamma$ 874T was associated with the development of allograft inflammation and fibrosis following lung transplantation. ${ }^{7}$ Conversely, IL- 10 is generally thought to inhibit the synthesis of a variety of pro-inflammatory molecules and downregulate immune responses. Once again, there are three single nucleotide polymorphisms at positions $-1082,-819,-592$ in the promoter region of the IL-10 gene reported. ${ }^{8}$ The ATA haplotype is associated with low IL-10 production and its presence has been linked to severe asthma. ${ }^{9}$ There is currently little information available about the possible interaction between these genes in terms of disease outcome, but it is likely that competing levels of pro-inflammatory and antiinflammatory cytokines will determine the course and outcome in many inflammatory diseases.

We therefore sought to address whether there was an association between the IFN $\gamma$ 874T and/or the IL-10 AT haplotype with disease or its outcome in intermediate uveitis. We have investigated polymorphism at IL-10 in positions -1082 and -819 only, as in the published data the polymorphism at -819 and -592 are in complete linkage disequilibrium.

\section{MATERIALS AND METHODS Patients}

Following informed consent, blood samples were collected by venepuncture from 125 patients with intermediate uveitis

Abbreviations: EAU, experimental autoimmune uveitis; IFN $\gamma$, interferon gamma; IL-10, interleukin 10; PCR, polymerase chain reaction; SNP, single nucleotide polymorphism 
attending the medical eye unit at St Thomas's Hospital, London. Patients with multiple sclerosis, sarcoidosis, Behçet's disease, seronegative arthropathy, inflammatory bowel disease or infectious or neoplastic uveitis at baseline, or who developed these diseases during follow up, were also excluded on the basis of clinical history, systemic examination, and relevant investigations. Patients with Fuchs' heterochromic cyclitis were excluded. All patients had bilateral disease. Healthy race matched individuals attending the clinical transplantation laboratory at Guy's Hospital, London, $(\mathrm{n}=100)$ provided blood as normal controls. The patients were managed by two senior ophthalmologists with a consistent philosophy to treatment and patient care was shared by the two clinicians throughout follow up. Outcome was defined as bad if the acuity of each eye was $<6 / 12$ Snellen in a quiet eye after 5 years. We did not include immunosuppressive treatment as a disease outcome measure since patients may require intensive treatment and still have a good outcome and vice versa. Patients with visual loss for reasons other than intraocular inflammation (for example, cataract, optic neuropathy, or amblyopia) were excluded from analysis.

\section{DNA extraction and PCR}

DNA was prepared by proteinase $\mathrm{K}$ digestion, and salt extraction ${ }^{10}$ and stored at $-70^{\circ} \mathrm{C}$ until use. Polymorphism in the promoter region of the IL- 10 gene at positions - $1082 \mathrm{G} / \mathrm{A}$ and $-819 \mathrm{C} / \mathrm{T}$ were detected by a PCR-SSP assay using four primer mixes.

$-1082 \mathrm{G}$ :

5' CAgTGCAACTgAgATTTgg 3'

5' CTACTAAggCTTCTTTgggAg 3'

$-1082 \mathrm{~A}$ :

5' CAgTGCAACTgAgAATTTg 3'

5'ACTACTAAggCTTCTTTgggAA 3'

$-819 \mathrm{C}$ :

5' AggATgTgTTCCAggCTCCT 3'

5' CCCTTgTACAggTgATgTAAC 3'

$-819 \mathrm{~T}$ :

5' AggATgTgTTCCAggCTCCT 3'

5' ACCCTTgTACAggTgATgTAAT 3' sense

The IFN $\gamma$ A874T polymorphism was also detected by PCRSSP using two primer mixes taken from Pravica et $\mathrm{al}^{6}$ :

$874 \mathrm{~T}$ :

5'TTCTTACAACACAAAATCAAATCT3'

5'TCAACAAAgCTgATACTCCA3'

874 A:

5'TTCTTACAACACAAAATCAAATCA 3'

5'TCAACAAAgCTgATACTCCA3'

The final volume of all polymerase chain reaction (PCR) reactions was $10 \mu \mathrm{l}$; the PCR reaction mixtures consisted of $67 \mathrm{mM}$ TRIS base pH 8.8, $16.6 \mathrm{mM}$ ammonium sulphate, $2 \mathrm{mM}$ magnesium chloride, $0.01 \%(\mathrm{v} / \mathrm{v})$ Tween $20,200 \mu \mathrm{M}$ of each dNTP, $1-4 \mu \mathrm{M}$ of each allele specific primer, $0.1 \mu \mathrm{M}$ of control primer, $0.1 \mu \mathrm{g}$ of DNA, and 0.1875 units of Taq Polymerase (Abgene, Epsom, UK). All reactions were carried out in a Geneamp PCR System 9700 thermal cycler (PE Biosystems, Foster City, CA, USA). PCR cycling conditions consisted of five cycles of $96^{\circ} \mathrm{C}$ for 25 seconds, $70^{\circ} \mathrm{C}$ for 45 seconds, and $72^{\circ} \mathrm{C}$ for 20 seconds, followed by 21 cycles of $96^{\circ} \mathrm{C}$ for 25 seconds, $65^{\circ} \mathrm{C}$ for 50 seconds, and $72^{\circ} \mathrm{C}$ for 45 seconds; and finally four cycles with $96^{\circ} \mathrm{C}$ for 25 seconds, $55^{\circ} \mathrm{C}$ for 60 seconds, and $72^{\circ} \mathrm{C}$ for 120 seconds. The PCR products were visualised by electrophoresis through a $1 \%$ agarose gel in 0.5X TBE buffer containing $100 \mu \mathrm{g} / \mathrm{l}$ ethidium bromide. The relative size of the PCR products was determined by comparison of the migration of a 1001000 bp DNA molecular weight ladder (Abgene, Epsom, UK). A permanent visual image was obtained using a
Table 1 Analysis of the IFN $\gamma$ A874T polymorphism in patients with intermediate uveitis and healthy controls

\begin{tabular}{|c|c|c|}
\hline IFN $\gamma$ A874T & $\begin{array}{l}\text { Intermediate uveitis } \\
\text { patients }\end{array}$ & Controls \\
\hline Genotype & $\mathrm{n}=125$ & $n=100$ \\
\hline$\pi$ & $38(30 \%)^{*}$ & 16 \\
\hline TA & $60(48 \%)$ & 50 \\
\hline AA & $27(22 \%)$ & 34 \\
\hline Allele & $\mathrm{n}=250$ & $n=200$ \\
\hline $\mathrm{T}$ & $136(54 \%) \dagger$ & $82(41 \%)$ \\
\hline A & $114(46 \%)$ & 118 (59\%) \\
\hline
\end{tabular}

ultraviolet illuminator and a UVP Imagestore 7500 (UVP Products Ltd, Cambridge, UK). The -1082 primers resulted in an amplicon of $258 \mathrm{bp}$ and the -819 primers an amplicon of 233. The IFN $\gamma$ primers resulted in an amplicon of 263 bases.

\section{Analysis of data}

Associations with disease were calculated by both allelic frequency and haplotype analysis. Associations between ocular disease outcomes and the presence of polymorphisms were identified by $\chi^{2}$ analysis with Yates's correction. Results are expressed as odds ratios (OR) with 95\% confidence intervals (95\% CI). A Bonferroni correction factor for the number of comparisons made was applied to the IFN $\gamma$ A874T analysis and the complex haplotype analysis with outcome (Pc).

\section{RESULTS}

In all, 125 patients were enrolled in the study; outcome data at 5 years were available for 102 patients; $62 \%$ were male with an age range of 21-76 years (mean 42 ) at last follow up. Of the 102 patients, 33 (33\%) had a bad outcome, all of whom showed irreversible macular damage. The definition of good or bad outcome was determined before the genotype study. All the genotypes tested were in Hardy-Weinberg equilibrium between groups and the -1082 haplotype frequency was similar to previous reported studies. ${ }^{8} 9$

Genotype analysis of the IFN $\gamma$ gene showed a greater prevalence of the $874 \mathrm{~T}$ allele in patients compared to controls $\left(54 \% \vee 41 \% \chi^{2}=7.9\right.$ Pc $=0.006$ OR $1.7 ; 95 \%$ CI 1.2 to 2.6 ). This was particularly striking for TT homozygotes, which were more prevalent in the patient group $(30 \% \vee 16 \%$, $\chi^{2}=6.3 \mathrm{PC}=0.02$ OR $2.3 ; 95 \%$ CI 1.1 to 4.7$)$, with a concomitant decrease in AA homozygotes (table 1).

We then addressed whether there was an association between disease outcome and the 874 SNP. There was a trend

Table 2 IL-10 haplotype and genotype for patients with intermediate uveitis and healthy controls

\begin{tabular}{lcc}
\hline IL-10 -1082 & Patients $(\mathbf{n = 1 2 5 )}$ & Controls $(\mathbf{n = 9 8 )}$ \\
IL-10-819 & & \\
\hline Haplotype analysis & $48(19 \%)$ & $48(24 \%)$ \\
AT & $67(27 \%)$ & $51(26 \%)$ \\
AC & $135(54 \%)$ & $97(50 \%)$ \\
GC & $9(7 \%)$ & 8 \\
Genotype analysis & $9(7 \%)$ & 12 \\
AT/AT & $12(10 \%)$ & 8 \\
AT/AC & $21(17 \%)$ & 20 \\
AC/AC & $34(27 \%)$ & 23 \\
AT/GC & $40(32 \%)$ & 27 \\
AC/GC & \\
GC/GC & \\
\hline &
\end{tabular}


Table 3 Association of IL-10-1082 AA with outcome

\begin{tabular}{lll}
\hline & Outcome & \\
\cline { 2 - 3 } & Good & Bad \\
\hline IL-10-1082 AA & $9 / 69(13 \%)$ & $15 / 33(46 \%)^{*}$ \\
AA & $3 / 11(27 \%)$ & $4 / 7(57 \%)$ \\
IL-10-1082 AA/IFN $\gamma 874$ & $6 / 18(33 \%) \dagger$ \\
AA/AA & $2 / 33(6 \%)$ & $5 / 8(63 \%) \dagger$ \\
AA/TA & $4 / 25(16 \%)$ & \\
AA/TT &
\end{tabular}

In patients for whom data were available $(n=73)$ the IL-10-1082AA genotype was more prevalent in those with bad compared to good outcome. When analysed on the basis of IL-10 - 1082AA and IFN $\gamma 874$ those patients expressing $874 \mathrm{~T}$ were more likely to have had a bad outcome.

*IL-10-1082 AA versus outcome $\chi^{2}=13 p=0.0003$ (Yates 0.0008) OR 5.6; $95 \% \mathrm{Cl} 1.9$ to 16.7 .

†IFN $\gamma$ T and IL-10 -1082 AA versus outcome $\chi^{2}=13.2 p=0.002$ (Yates $0.002)$ OR $6.3 ; 95 \% \mathrm{Cl} 1.8$ to 23.6 .

towards the $874 \mathrm{~T}$ allele being more prevalent in patients with a bad disease outcome $(56 \% v 45 \% \mathrm{p}=0.5)$ but this did not reach significance.

The IL-10 haplotype was analysed in the same group of patients. In all cases $-1082 \mathrm{G}$ was linked to $-819 \mathrm{C}$, although $-1082 \mathrm{~A}$ was associated with both $-819 \mathrm{C}$ and $-819 \mathrm{~T}$, therefore the GT haplotype was not observed. There was no association with either $-1082 \mathrm{~A}$ alone, the AT haplotype, or any of the -1082 genotypes and disease in patients (table 2). When analysed on the basis of outcome, IL-10-1082AA homozygosity was strongly associated with bad outcome $\left(46 \%\right.$ v $13 \% ; \chi^{2}=13$ PC $=0.0008$ OR $5.695 \%$ CI 1.9 to 16.7$)$ (table 3).

We next analysed the two polymorphisms as a complex haplotype. All genotypes of 874 and the AA homozygous -1082 were compared with disease outcome. Of those patients with a bad outcome 57\% were AA/AA, 33\% AA/TA, and $63 \%$ AA/TT compared to $27 \%, 6 \%$, and $16 \%$, respectively for patients with a good outcome. When those patients with AA - 1082/all 874 genotypes were compared to other - 1082/ all 874 genotypes based on outcome, the result was significant $\left(\chi^{2}=13.2\right.$ PC $=0.002$ OR $6.3 ; 95 \%$ CI 1.85 to 23.6) (table 3). However, this did not remain significant after application of a Bonferroni correction factor for the number of comparisons made. Therefore, there was a trend for patients with bad outcome to have IL-10-1082 AA genotype in association with any IFN $\gamma$ 874T genotype compared to patients with a good outcome. This was particularly prominent in those patients with 874 TT.

\section{DISCUSSION}

Interferon $\gamma$ production is the hallmark of a Thl response and polymorphisms in its gene that result in higher production for a given stimulus might be expected to produce more severe inflammation and tissue destruction. In this study of patients with intermediate uveitis, the IFN $\gamma$ A874T polymorphism, which reflects a constitutively higher production of IFN $\gamma$, was significantly associated with disease and, although not statistically significant, there was a trend towards an association with disease outcome. Although not significant alone, the IL-10-1082AA haplotype was associated with bad outcome when analysed in conjunction with IFN $\gamma 874$ haplotypes. In particular, the -1082AA/874TT haplotype that would produce low IL-10 and high IFN $\gamma$ was present in almost half the -1082 AA patients with bad outcome, compared to only $16 \%$ of those with a good outcome. Increased production of IFN $\gamma$ in patients with intermediate uveitis would induce increased MHC class I and class II expression, intercellular adhesion molecule-1, and inducible nitric oxide synthetase, all of which have been shown to be raised in intermediate uveitis and lead to lymphocyte infiltration and tissue damage. ${ }^{11-13}$ By comparison, low IL-10 would lead to a decrease in regulation and a subsequent increase in the Thl response and thus to more severe disease. ${ }^{14}$

The role of cytokines in uveitis is complex. Significant levels of cytokine mRNA and protein were found in cells taken from the aqueous humour of patients with uveitis and indicated a Thl profile. ${ }^{15}{ }^{16}$ Levels of both IFN $\gamma$ and IL- 10 in the serum were elevated in patients with uveitis, while only IFN $\gamma$ was raised in aqueous humour samples from patients with uveitis compared to cataract controls. ${ }^{17}$ In patients with infectious uveitis, both IFN $\gamma$ and IL-10 were detected in significantly more aqueous samples and at higher levels compared to control samples. ${ }^{18}$ Similarly, in EAU, uveitogenic cells have a Thl profile and genetic susceptibility to disease induction is associated with an increased Thl response. ${ }^{19}$ Paradoxically, neutralisation of IFN $\gamma$ exacerbated EAU, which may be explained by studies in IFN $\gamma$ deficient mice challenged with interphotoreceptor binding protein who developed EAU comparable in severity to wild type mice, with an excessive granulocyte infiltration and increased IL-5, IL-6, and IL-10..$^{21}$ These data demonstrate that IFN $\gamma$, in addition to a pathogenic role, has a protective capacity in uveitis. Such competing mechanisms support the complex nature of cytokine interactions in inflammatory disease.

Similarly, IL-10 can influence the inflammatory response at several points. Firstly, in the initial stage of bacterial or viral infections or at sites of tissue damage, IL-10 induces activation of natural killer cells and macrophage phagocytosis. ${ }^{22}$ Secondly, as the adaptive immune response develops, IL-10 inhibits Thl cells and macrophage activation, by inhibition of expression of co-stimulatory molecules and pro-inflammatory cytokines. ${ }^{23}$ Thirdly, IL- 10 has been shown to be a pivotal mediator of regulatory $\mathrm{T}$ cells ${ }^{24}$ and the ATA haplotype may be associated with reduced numbers or effectiveness of such cells. EAU resistant F344 rats express higher basal levels of IL-10 mRNA in ocular tissue, while susceptible strains have low levels, and it has been suggested that higher expression of the IL-10 gene may contribute to a higher threshold of resistance to EAU. ${ }^{25}$ In support of a protective role for IL-10, mice given viral IL-10, that retains immunosuppressive but not immune activation function, before induction of EAU showed less ocular pathology and lower IFN $\gamma$ and IL-2 production by antigen challenged splenocytes. ${ }^{26}$ It should be noted that these mechanisms are controversial in animal models and have not be shown to be active in humans. Moreover, other SNP have been reported in the genes encoding IL-10 and IFN $\gamma$ that may also influence production of these cytokines. ${ }^{27} 28$

A number of potential sources of bias arise concerning our clinical data. Firstly, the study population may have shown a selection bias towards patients with poor outcome. The patient population was derived from a tertiary referral centre and, although patients are followed as a routine for extended periods, those who had mild disease or in whom disease had regressed may have been lost to follow up. Accordingly, only patients with more severe disease may have been included in the analysis. Secondly, since this was a review of case records to determine outcome, it is possible that further improvements in visual acuity after 5 years might have been possible with more aggressive treatment-that is, the best recorded visual acuity at the end of follow up was not necessarily the best possible. However, in all cases, the patients were seen by senior ophthalmologists experienced in the management of intraocular inflammation during the fifth year making this less likely. Furthermore, any bias introduced by inconsistencies in treatment was avoided by recording the acuity when 
disease was quiet. Thirdly, the clinical homogeneity of the population studied may be questioned. Although unlikely, it is still possible that patients who only had isolated disease confined to the eye would have developed an associated systemic disease after 5 years. For instance, multiple sclerosis has been reported to occur after 7 years of follow up, and a recent study showed that the mean time from the onset of posterior uveitis to development of multiple sclerosis was 8.5 years. $^{29} 30$

Uveitis is mediated by cytokines that may exacerbate or ameliorate disease depending on level and time of production. Of the cytokines in the current study, IFN $\gamma$ is generally deleterious while IL-10 is protective, and the production of both has been demonstrated to be under genetic control. The results presented here suggest the possibility that a complex haplotype based on low production of IL-10 and high production of IFN $\gamma$ can be associated with a bad visual outcome in patients with intermediate uveitis. Furthermore, our results may have therapeutic implications since there is considerable interest in using monoclonal antibodies against cytokines in treatment, and the ability to tailor immunoregulatory regimes to a patient's genetic background would make this more rational. To our knowledge this is the first demonstration of a genetic basis for outcome of intermediate uveitis. While it is clear that other mediators and polymorphisms will be involved in the onset and outcome of disease, these results show that identification of complex genotypes may distinguish, at an early stage those patients likely to progress to severe disease and be treated accordingly.

\section{ACKNOWLEDGEMENTS}

This work was supported by the Guide Dogs for the Blind Association and The Iris Fund for the Prevention of Blindness.

\section{Authors' affiliations}

M R Stanford, R Y Chen, E M Graham, G R Wallace, Departments of Ophthalmology, Guy's, King's and St Thomas's Hospital Medical Schools, London, UK

R W Vaughan, E Kondeatis, Clinical Transplantation Laboratory, Guy's, King's and St Thomas's Hospital Medical Schools, London, UK

C E Edelsten, Department of Ophthalmology, Ipswich General Hospital, UK

G R Wallace, Academic Unit of Ophthalmology, University of Birmingham, Birmingham, UK

Competing interests: none declared

This study received ethical approval from the St Thomas's Research Ethics Committee.

\section{REFERENCES}

1 Stanbury RM, Wallace GR, Graham EM. Intermediate uveitis: pars planitis, multiple sclerosis, and retinal vasculitis. Ophthalmol Clin N Am 1998; 11:627-39.

2 Butcher EC, Picker $\amalg$. Lymphocyte homing and homeostasis. Science 1996;272:60-6

3 Forrester JV. Uveitis: pathogenesis. Lancet 1991;338:1498-501.
4 Sun B, Sun SH, Chan CC, et al. Autoimmunity to a pathogenic retinal antigen begins as a balanced cytokine response that polarizes towards type 1 in a disease-susceptible and towards Th2 in a disease-resistant genotype. Int Immunol 1999;11:1307-12.

5 Pravica V, Asderakis A, Perrey C, et al. In vitro production of IFN-gamma correlates with CA repeat polymorphism in the human IFN- $\gamma$ gene. Eur J Immunogenet 1999;26:1-3.

6 Pravica V, Perrey C, Stevens A, et al. A single nucleotide polymorphism in the first intron of the human IFN- $\gamma$ gene. Hum Immunol 2000;61:863-6.

7 Lu KC, Jaramillo A, Lecha RL, et al. Interleukin- 6 and interferon- $\gamma$ gene polymorphisms in the development of bronchiolitis obliterans syndrome after lung transplantation. Transplantation 2002;74:1297-302.

8 Turner DM, Williams DM, Sankaran D, et al. An investigation of polymorphism in the interleukin-10 gene promoter. Eur J Immunogenet 1997; 24: 1-8

9 Lim S, Crawley E, Woo P, et al. Haplotype associated with low interleukin-10 production in patients with severe asthma. Lancet 1998;352:113.

10 Miller SA, Dykes DD, Polesky HF. A simple salting out procedure for extracting DNA from human nucleated cells. Nucleic Acids Res 1988;16:1215.

11 Hooks JJ, Chan CC, Detrick B. Identification of lymphokines, interferongamma, and IL-2 in inflammatory eye disease. Invest Ophthalmol Vis Sci 1988;29:1444-51.

12 Whitcup SM, Butler KM, Pizzo PA, et al. Expresssion of cell adhesion molecules in posterior uveitis. Arch Ophthalmol 1992;110:662-9.

13 Rao NA, Wu GS. Free radical mediated photoreceptor damage in uveitis. Prog Ret Eye Res 2000;19:41-68.

14 Rizzo LV, Xu H, Chan CC, et al. IL-10 has a protective role in experimental autoimmune uveoretinitis. Int Immunol 1998;10:807-14.

15 Murray PI, Clay CD, Mappin C, et al. Molecular analysis of resolving immune responses in uveitis. Clin Exp Immunol 1999;117:455-61

16 Muhaya M, Calder V, Towler HMA, et al. Characterization of T cells and cytokines in the aqueous humour $(\mathrm{AH})$ of patients with Fuch's heterochromic cyclitis (FHC) and indiopathic anterior uveitis (IAU) Clin Exp Immunol 1998;111:123-8.

17 Lacomba MS, Martin CM, Chammond RR, et al. Aqueous and serum interferon gamma, interleukin (IL)-2, IL-6 and IL-10 in patients with uveitis. Arch Ophthalmol 2000;118:768-72.

18 Ongkosuwito JV, Feron EJ, van Doornik CE, et al. Analysis of immunoregulatory cytokines in ocular fluid samples from patients with uveitis. Invest Ophthalmol Vis Sci 1998;39:2659-65.

19 Caspi RR, Silver PB, Chan CC, et al. Genetic susceptibility to experimental uveoretintis in the rat is associated with an elevated Th1 response. J Immunol 1996;157:268-75

20 Caspi RR, Chan CC, Grubbs BG, et al. Endogenous systemic IFN $\gamma$ has a protective role against ocular autoimmunity in mice. J Immunol $1994 ; 152: 890$

21 Jones LS, Rizzo LV, Agarwal RK, et al. IFN $\gamma$-deficient mice develop experimental autoimmune uveitis in the context of a deviant effector response. $J$ Immunol 1997; 158:5997-6005.

22 Mocellin S, Panelli MC, Wang E, et al. The dual role of IL-10. Trends Immunol 2003;24:36-43.

23 Moore KW, de Waal Malefyt R, Coffman RL, et al. Interleukin-10 and the interleukin receptor. Ann Rev Immunol 2001; 19:683-765.

24 Groux H, O'Garra A, Bigler M, et al. Generation of a novel regulatory $C D 4^{+} \mathrm{T}$ cell population which inhibits antigen-specific $T$ cell responses. Nature 1997:389:737-42.

25 Sun B, Sun SH, Chan CC, et al. Evaluation of in vivo cytokine expression in EAU susceptible and resistant rats: a role for IL-10 in resistance. Exp Eye Res 2000;70:493-502.

26 De Kozak Y, Thillaye-Goldenberg B, et al. Inhibition of experimental autoimmune uveoretintis by systemic and subconjunctival adenovirus transfer of the viral IL-10 gene. Clin Experiment Immunol 2002;130:212-23.

27 Eskdale J, Gallagher G, Verweij CL, et al. Interleukin-10 secretion related to human Il-10 haplotypes. Proc Natl Acad Sci 1998;95:9465-70.

28 Warle MC, Farhan A, Metselaar HJ, et al. Are cytokine gene polymorphisms related to in vitro cytokine production profiles. Liver Trans 2003:9:170-81.

29 Malinowski SM, Pulido S, Folk JC. Long-term visual outcome and complications associated with pars planitis. Ophthalmology 1993;100:818-24

30 Masterman T, Ligers A, Olsson T, et al. HLA-DR15 is associated with lower age at onset in multiple sclerosis. Ann Neurol 2000;48:211-19. 